TITLE:

\title{
Characterization of lignin-derived products from Japanese cedar as treated by semi-flow hot- compressed water
}

\author{
AUTHOR(S): \\ Takada, Masatsugu; Saka, Shiro
}

CITATION:

Takada, Masatsugu ...[et al]. Characterization of lignin-derived products from Japanese cedar as treated by semi-flow hot-compressed water. Journal of Wood Science 2015, 61(3): 299-307

ISSUE DATE:

2015-02-13

URL:

http://hdl.handle.net/2433/201513

\section{RIGHT:}

The final publication is available at Springer via http://dx.doi.org/10.1007/s10086-015-1464-0.; The full-text file will be made open to the public on 13 February 2016 in accordance with publisher's 'Terms and Conditions for Self-Archiving'; This is not the published version. Please cite only the published version.; この論文は出版社版でありません。引用の際 には出版社版をご確認ご利用ください。 
1 Characterization of lignin-derived products from Japanese

2 cedar as treated by semi-flow hot-compressed water 3

4 Masatsugu Takada $\cdot$ Shiro Saka

5

6

$7 \quad$ Affiliation

8

9 Department of Socio-Environmental Energy Science, Graduate School of Energy

10 Science, Kyoto University, Yoshida-honmachi, Sakyo-ku, Kyoto 606-8501, Japan

11 Tel. +81-75-753-4738; Fax: +81-75-753-4738

12 e-mail: saka@energy.kyoto-u.ac.jp

15 Abstract

16

17 In order to elucidate the decomposition behavior of lignin from Japanese cedar

18 (Cryptomeria japonica) as treated by two-step semi-flow hot-compressed water $\left(1^{\text {st }}\right.$

19 stage: $230{ }^{\circ} \mathrm{C} / 10 \mathrm{MPa} / 15 \mathrm{~min}, 2^{\text {nd }}$ stage: $270{ }^{\circ} \mathrm{C} / 10 \mathrm{MPa} / 15 \mathrm{~min}$ ), water-soluble portion, 
20 precipitate and water-insoluble residue obtained by hot-compressed water treatment

21 were separated and characterized. Consequently, the water-soluble portion was found to

22 contain lignin-derived monomeric compounds such as coniferyl alcohol and coniferyl

23 aldehyde and $\beta-1, \beta-5$ and $5-5$ ' linked dimeric compounds. These lignin-derived

24 compounds maintained methoxyl and phenolic hydroxyl groups in aromatic rings. The

25 water-soluble portion also contained lignin-derived oligomeric compounds up to

26 heptamers. In contrast, the precipitate was found out to consist of higher molecular

27 weight lignin with high ether type linkages. The water-insoluble residue, however,

28 consisted mostly of lignin with high condensed type linkages. Based on these lines of

29 evidence, condensed type lignin must be resistant to hot-compressed water, remained as

30 water-insoluble residue after two-step treatment. Such information provides a clue as to

31 efficient utilization of lignin-derived products.

33 Keywords Japanese cedar, Hot-compressed water, Lignin-derived products,

34 condensed type lignin 


\section{Introduction}

37 The wood cell wall consists mainly of cellulose, hemicelluloses and lignin, and these

38 compounds are composed intricately in an artful manner to enforce the wood cell wall,

39 having a resistance to water and most organic solvents. Among the natural polymers,

40 lignin is the second most abundant macromolecule with $24-33 \%$ in softwoods and

$41 \quad 19-28 \%$ in hardwoods [1]. Since lignin may become a resource of energy and valuable

42 aromatic chemicals due to its abundance, various degradation methods have been

43 studied for its utilization. Among them, hydrothermal treatments such as steam

44 explosion, subcritical and supercritical water and hot-compressed water are catalyst-free and environmentally benign. An increase in temperature of water at a high pressure results in a decrease in its dielectric constant and an increase in its ionic product $[2,3]$.

47 Moreover, decreased dielectric constant of water enhances solubility of some hydrophobic compounds into subcritical and supercritical water.

Tanahashi et al. examined the degradation mechanism of lignin by steam explosion

$50\left(230{ }^{\circ} \mathrm{C} / 2.9 \mathrm{MPa} / 16 \mathrm{~min}\right)$ with dehydrogenated polymer of coniferyl alcohol and $\beta-O-4$

51 linkage model compounds [4]. Ehara et al. [5] and Takada et al. [6] treated Japanese

52 beech (Fagus crenata) and Japanese cedar (Cryptomeria japonica) with supercritical water (380-400 $\left.{ }^{\circ} \mathrm{C} / 100-115 \mathrm{MPa} / 5-8 \mathrm{sec}\right)$. Consequently obtained lignin-derived 
54 compounds were fractionated as methanol-soluble portion but water-insoluble oily

55 products were composed of monomeric aromatic and condensed type dimeric

56 compounds. Yokoyama et al. treated organosolv lignin with supercritical water (350-420

$57{ }^{\circ} \mathrm{C} / 10-40 \mathrm{MPa} / 60 \mathrm{~min}$ ), and the resultant yields of oil and char were dependant on the

58 treatment condition [7]. Saisu et al. [8] and Okuda et al. [9] also treated organosolv

59 lignin with supercritical water $\left(400{ }^{\circ} \mathrm{C} /\right.$ pressure not given/10-64 min) and obtained

60 reactive compounds such as formaldehyde and lignin-derived monomeric compounds

61 such as guaiacol, catechol and phenol were obtained due to hydrolysis and the

62 subsequent dealkylation. They explained that low molecular weight compounds were

63 reactive such that they reacted with residual lignin to become high molecular weight

64 residue.

65

Phenol and aromatic nuclear are known to be stable to supercritical water treatment

66 through some experiments with various monomeric lignin model compounds [10-15].

67 The resistance of lignin to supercritical water differs, dependent on the types of its

68 linkages, and ether linkages in lignin are readily cleaved by protic solvent such as

69 supercritical water and methanol, while condensed type of linkages and aromatic ring

70 are difficult to be cleaved [16,17].

71 Recently, hot-compressed water, a milder condition for hydrothermal reaction with

72 high ionic products, has gained considerable attention as a promising decomposition 
73 medium for lignocelluloses [3], and the hot-compressed water treatment system could

74 be simply categorized into batch, flow, and semi-flow (percolation) types. Since the

75 decomposition reaction becomes dominant in batch and flow type treatments, some

76 products are excessively decomposed, whereas semi-flow type treatment can prevent

77 products from excessive decomposition due to the short residence time $[18,19]$. Lignin

78 also can be depolymerized and decomposed by semi-flow hot-compressed water [20].

79 Lu et al. treated Japanese beech (Fagus crenata) with two-step semi-flow

80 hot-compressed water $\left(1^{\text {st }}\right.$ stage: $230{ }^{\circ} \mathrm{C} / 10 \mathrm{MPa} / 15 \mathrm{~min}, 2^{\text {nd }}$ stage: $270{ }^{\circ} \mathrm{C} / 10 \mathrm{MPa} / 15$

$81 \mathrm{~min}$ ) and the hemicelluloses and cellulose were selectively decomposed [21]. They also

82 elucidated that lignin was decomposed in both stages and the lignin-derived monomeric

83 products such as coniferyl alcohol and sinapyl alcohol were obtained in water-soluble

84 portion [21]. Yamauchi et al. showed that hot-compressed water can cleave only ether

85 linkages of lignin through the structural analysis of lignin-derived products [22].

86 Additionally, these lignin-derived products could be converted into acetic acid and

87 phenolic compounds via microorganism, thus, these are expected to become valuable 88 chemicals [23].

89 Phaiboonsilpa et al. treated Japanese cedar (Cryptomeria japonica) and obtained

90 lignin-derived products with hot-compressed water [24]. However, detailed analysis of 91 the lignin-derived products obtained from Japanese cedar has not yet been conducted. 
92 Yamauchi et al. have studied the decomposition behavior of lignin in Japanese beech as

93 described above [22], while lignin content and its structure in Japanese cedar are

94 different from Japanese beech, and their decomposition behaviors of lignin should also

95 differ. Thus, the aim of this study is to analyze the lignin-derived products in order to

96 elucidate the decomposition behavior of lignin from Japanese cedar as treated by

97 hot-compressed water.

98

99

100 Materials and methods

101

102 Wood sample and chemicals

103

104 Wood flour of Japanese cedar (Cryptomeria japonica) passing through an 18-mesh

105 screen was extracted with acetone using Soxhlet apparatus, and dried at $105{ }^{\circ} \mathrm{C}$ for $24 \mathrm{~h}$

106 before experiment. All chemicals used in this study were of reagent grade without

107 purification.

108

109 Two-step semi-flow hot-compressed water treatment 
111 Approximately $0.5 \mathrm{~g}$ of oven-dried extractive-free wood flour was placed in the reaction

112 vessel for which the two-step semi-flow hot-compressed water treatment was performed

113 as described in a previous paper [24]. Two-step treatment conditions were $230{ }^{\circ} \mathrm{C} / 10$

$114 \mathrm{MPa} / 15 \mathrm{~min}$ for the $1^{\text {st }}$ stage and $270{ }^{\circ} \mathrm{C} / 10 \mathrm{MPa} / 15 \mathrm{~min}$ for the $2^{\text {nd }}$ stage. After

115 treatment, hot-compressed water-insoluble residue left over in the reaction vessel was

116 separated from hot-compressed water-soluble portion and dried at $105{ }^{\circ} \mathrm{C}$ for $12 \mathrm{~h}$ to

117 measure its oven-dried weight. The separated hot-compressed water-soluble portion was

118 kept standing for $12 \mathrm{~h}$ under ambient condition. During this period, it was separated to

119 be water-soluble portion and precipitate which were retrieved by filtration with

120 Millipore (pore size: $0.45 \mu \mathrm{m}$ ). For the water-soluble portion, the lignin-derived

121 compounds were obtained by extraction with ethyl acetate.

123 Analytical methods

125 The content of lignin-derived products in each fraction was examined as the combined

126 yields of Klason lignin and acid-soluble lignin [25]. For the acid-soluble portion

127 obtained, the amounts of various mono-saccharides were determined by high

128 performance anion-exchange chromatography. Its cellulose and hemicellulose contents

129 were then estimated based on the amounts of glucose and other mono-saccharides, 
130 respectively [26]. Molecular weight distribution was evaluated by gel permeation

131 chromatography (GPC) analysis, which was performed with LC-10A (Shimadzu, Kyoto,

132 Japan) under the following conditions: column, Shodex KF-801 + KF-802 + KF-802.5

$133+$ KF-803 (Showa Denko, Tokyo, Japan); eluent, tetrahydrofuran; flow-rate, 0.6

$134 \mathrm{~mL} / \mathrm{min}$; column temperature, $50{ }^{\circ} \mathrm{C}$; detector, Ultraviolet light at $280 \mathrm{~nm}$. For

135 comparison, polystyrene standards (Molecular weight (MW): 162, 580, 1270, 2960,

136 5000) were used as standard.

137 In order to evaluate chemical characteristics of lignin-derived products, alkaline

138 nitrobenzene oxidation was performed and gas chromatographic analysis was

139 undertaken to obtain the total yield of vanillin [27]. However, since water-soluble

140 portion contained some monomeric products like coniferyl alcohol, the vanillin yield

141 from oligomeric products was evaluated from the total yield of vanillin minus vanillin

142 from monomeric products, according to the following equation (1):

143

$=\frac{\text { Total yield of vanillin }(\mathrm{mmol})-\text { Yield of vanillin from monomeric lignin }- \text { derived products }(\mathrm{mmol})}{\text { Lignin }- \text { derived products }(\mathrm{g})-\text { Monomeric lignin }- \text { derived products }(\mathrm{g})}$

146 Since monomeric compounds are mostly composed of conferyl alcohol, coniferyl

147 aldehyde, vanillin and isoeugenol, other monomeric products were ignored in this

148 calculation. 
149 Monomeric and dimeric compounds of lignin-derived products in water-soluble

150 portion were analyzed by gas chromatography - mass spectrometry (GC-MS), which

151 was performed with Hitachi M7000s and M9000 series. The capillary column was a

152 DB-5MS. The temperature program was $1.0 \mathrm{~min}$ at $40{ }^{\circ} \mathrm{C}, 5.0{ }^{\circ} \mathrm{C} / \mathrm{min}$ to $300{ }^{\circ} \mathrm{C}$, and 8.0

$153 \mathrm{~min}$ at $300{ }^{\circ} \mathrm{C}$. Helium carrier gas was used at a flow-rate of $1.5 \mathrm{~mL} / \mathrm{min}$. Injector and

154 detector temperatures were both $230{ }^{\circ} \mathrm{C}$.

155 High molecular weight compounds of lignin-derived products in water-soluble

156 portion were analyzed by matrix-assisted laser desorption ionization-time of flight /

157 mass spectrometry (MALDI-TOF/MS), which was performed with AXIMA

158 Performance (Shimadzu, Kyoto, Japan). Nitrogen gas was used as the laser source. The

159 analysis was performed in positive-ion, linear mode and 2,5-dihydroxybenzaldehyde

160 was used as matrix.

161

162

163 Results and discussion

164

165 Lignin-derived products

166

167 The temperature change of hot-compressed water treatment for the $1^{\text {st }}$ stage $\left(230{ }^{\circ} \mathrm{C} / 10\right.$ 
$168 \mathrm{MPa} / 15 \mathrm{~min})$ and $2^{\text {nd }}$ stage $\left(270{ }^{\circ} \mathrm{C} / 10 \mathrm{MPa} / 15 \mathrm{~min}\right)$ is shown in Fig. 1 . The yield of

169 water-insoluble residue and its chemical composition are also shown. When

170 extractive-free Japanese cedar is treated by hot-compressed water, hemicelluloses and a

171 part of cellulose are decomposed and eluted as hot-compressed water-soluble portion at

172 the $1^{\text {st }}$ stage, and then in the $2^{\text {nd }}$ stage, the rest of cellulose is mostly decomposed and

173 eluted. It seems likely that cellulose decomposed in the $1^{\text {st }}$ stage might have lower

174 crystallinity compared with remaining cellulose decomposed in the $2^{\text {nd }}$ stage. In contrast,

175 lignin is decomposed at both stages recovered as lignin-derived products in all fractions.

176 However, some of lignin has much higher resistance to hot-compressed water as

177 compared with cellulose and hemicelluloses. The hot-compressed water-soluble portion

178 eluted is later partially precipitated under ambient conditions.

179 The yields of water-soluble portion, precipitate, and water-insoluble residue in both

180 stages are summarized in Table 1. In addition, the yield of the lignin-derived products

181 and the lignin concentration in each fraction are also shown. In the $1^{\text {st }}$ stage, $52.1(=$

$18247.1+5.0) \%$ of Japanese cedar was eluted in hot-compressed water, and $5.0 \%$ was

183 obtained as precipitate. Consequently, $47.1 \%$ was obtained in water-soluble portion and

$18447.9 \%$ remained as water-insoluble residue. After the $2^{\text {nd }}$ stage treatment of the

185 water-insoluble residue $(47.9 \%), 35.1(=29.8+5.3) \%$ was eluted in hot-compressed

186 water, and then $5.3 \%$ and $29.8 \%$ were obtained as precipitate and water-soluble portion, 
187 respectively. As a result, $12.8 \%$ of Japanese cedar remained as water-insoluble residue

188 after two-step treatment. This value is, in fact, much higher than that of Japanese beech

189 only to be $4.4 \%$ [22]. The observed difference in lignin between the two woods would

190 be due to the fact that Japanese cedar has less ether linkages than Japanese beech.

191 The yields of lignin-derived products in each fraction are shown in extractive-free

192 wood-based wt \%. For the $32.0 \%$ lignin content of Japanese cedar, $14.0(=10.1+$

193 3.9) \% was eluted in hot-compressed water at the $1^{\text {st }}$ stage, with $10.1 \%$ and $3.9 \%$ being

194 from water-soluble portion and precipitate, respectively. In the $2^{\text {nd }}$ stage, $6.8 \%(=5.0+$

195 1.8) was resulted with $5.0 \%$ and $1.8 \%$ as water-soluble portion and precipitate,

196 respectively. On the other hand, $11.2 \%$, about one third of the initial lignin content, still

197 remained as water-insoluble residue after two-step treatment.

198 The lignin concentration was $0.214 \mathrm{~g} / \mathrm{g}$ and $0.168 \mathrm{~g} / \mathrm{g}$ for water-soluble portion in

199 both $1^{\text {st }}$ and $2^{\text {nd }}$ stages, respectively. For precipitate, the lignin concentration in the $1^{\text {st }}$

200 stage was $0.780 \mathrm{~g} / \mathrm{g}$, whereas that in the $2^{\text {nd }}$ stage was much lower to be $0.340 \mathrm{~g} / \mathrm{g}$. This

201 difference could indicate that high molecular weight cellulose-derived products, eluted

202 in the $2^{\text {nd }}$ stage, aggregated and precipitated with lignin-derived products under ambient

203 condition [28]. A similar tendency was observed in the case of Japanese beech [22]. The

204 lignin concentration of the water-insoluble residue increased as the hot-compressed 
$206 \mathrm{~g} / \mathrm{g}$ ), indicating that the residual lignin has much higher resistance to hot-compressed

207 water than other chemical components.

208

209 Structural analysis of lignin-derived products

210

211 Fig. 2 demonstrates GPC chromatograms of water-soluble portion and precipitate of

212 both stages, detected at $280 \mathrm{~nm}$ in wavelength. In order to evaluate the molecular weight

213 distribution of their lignin-derived products, the elution time of polystyrene standards

214 (MW: 162, 580, 1270, 2960, 5000) were displayed. The higher molecular weight

215 standards show the shorter elution time in GPC chromatograms. The chromatogram of

216 water-soluble portion in the $2^{\text {nd }}$ stage has an intensive peak at around $63 \mathrm{~min}$, which

217 indicates 5-hydroxymethylfurfural derived from polysaccharides.

218 For the water-soluble portion, the lignin-derived products in the $1^{\text {st }}$ stage contain

219 oligomeric products up to MW of 1270, equivalent to heptamer of coniferyl alcohol,

220 whereas the lignin-derived products in the $2^{\text {nd }}$ stage contain smaller than those in the $1^{\text {st }}$

221 stage. In contrast, the molecular weight of the precipitate lignin is higher than the

222 lignin-derived products in water-soluble portion for both stages.

223 In order to compare the relative proportion of ether linkages of lignin-derived

224 products, alkaline nitrobenzene oxidation was conducted, and the obtained yield of its 
225 products from the lignin-derived products is shown in Fig.3. Since

$226 p$-hydroxybenzaldehyde derived from $p$-hydroxyphenylpropane $(\mathrm{H})$ lignin was a trace

227 amount, the yield of vanillin derived from guaiacyl $(\mathrm{G})$ lignin was only shown. For

228 comparison, the yield of vanillin from the untreated Japanese cedar is also shown. Since

229 water-soluble portion contains some monomeric products like coniferyl alcohol as

230 already described, the vanillin yield from oligomeric products was obtained by

231 subtracting vanillin yield from monomeric products from the total yield of vanillin.

232 For the water-soluble portion, the yields of vanillin from the $1^{\text {st }}$ and $2^{\text {nd }}$ stages are

2330.64 and $0.38 \mathrm{mmol} / \mathrm{g}$ of original lignin, respectively, both of which are smaller than the

234 vanillin derived from untreated wood $(1.53 \mathrm{mmol} / \mathrm{g})$. This suggests that the

235 lignin-derived products of water-soluble portion contain a lower ratio of ether type

236 lignin than untreated wood lignin. On the other hand, the yields of vanillin from

237 precipitate lignin in both stages were comparable to that from untreated wood. This

238 could indicate that precipitate lignin maintains ether linkages. For water-insoluble

239 residue, the yield of vanillin from the $1^{\text {st }}$ stage is $0.63 \mathrm{mmol} / \mathrm{g}$, whereas that from $2^{\text {nd }}$

240 stage $0.17 \mathrm{mmol} / \mathrm{g}$, decreasing in its yield as the hot-compressed water treatment

241 progressed. Consequently, lignin in the water-insoluble residue, especially for $2^{\text {nd }}$ stage,

242 is rich in condensed type lignin. 
244 Lignin-derived products in water-soluble portion

246 In order to identify lignin-derived low molecular weight compounds in water-soluble

247 portion, GC-MS analysis was performed. GC-MS spectrum of lignin-derived products

248 in water-soluble portion is shown in Fig. 4. The peaks in the short retention time before

$24935 \mathrm{~min}$ are lignin-derived monomeric compounds, while those in the longer retention

250 time after 35 min are dimeric compounds.

251 According to the comparison with lignin monomeric model compounds, 17 kinds of

252 lignin-derived compounds such as vanillin (No. 5), isoeugenol (No. 6), coniferyl

253 aldehyde (No. 17), and coniferyl alcohol (No. 18) are identified as shown in Table 2.

254 Some lignin-derived products were identified from their mass spectra by comparing

255 their retention times with those of authentic compounds as in the literature $[6,29,30]$.

256 Consequently, these identified compounds contained guaiacol skeletons, indicating that

257 the methoxyl group has not been removed from aromatic ring by hot-compressed water

258 treatment. These compounds also contain phenolic hydroxyl group. Most of this

259 hydroxyl group could be produced due to the cleavage of ether linkages by

260 hot-compressed water treatment. Among these identified compounds, trans-coniferyl

261 alcohol is obtained as the main product. It would mean that the lignin-derived products

262 in water-soluble portion largely maintain the side-chain structure of lignin. A few of 
263 ketone compounds, which are characteristic products from acidolysis of lignin, are

264 observed in water-soluble portion. Thus, acidolysis reaction can be ignored in the

265 hot-compressed water treatment.

266 Takada et al. obtained the lignin-derived compounds from Japanese cedar

267 (Cryptomeria japonica) by supercritical water treatment $\left(380{ }^{\circ} \mathrm{C} / 100 \mathrm{MPa} / 8 \mathrm{sec}\right)$ as

268 methanol-soluble portion, and analyzed the lignin-derived monomeric and dimeric

269 compounds with GC-MS [6]. The lignin-derived monomeric products in

270 methanol-soluble portion contained guaiacol skeletons, indicating that the methoxyl

271 group had not been removed from aromatic ring by supercritical water treatment. In

272 addition, vanillin was mainly obtained without recovered coniferyl alcohol. Thus, the

273 side-chain structure in lignin was more altered by supercritical water treatment

274 compared with hot-compressed water treatment. This suggests that hot-compressed

275 water treatment used in this study can suppress the decomposition of side-chain in

276 lignin more effectively than supercritical water treatment.

277 Table 3 demonstrates mass fragments and retention time of lignin-derived dimeric

278 compounds. Among these compounds, Nos. 20, 26, and 31 in Fig. 5 are identified from

279 their mass spectra by comparing their retention times with those of authentic

280 compounds as in the literature and the number of hydroxyl groups, estimated from the

281 increase of molecular weight after trimethylsilyl derivatization [6]. These identified 
282 compounds are condensed type, containing methoxyl and phenolic hydroxyl groups as

283 observed in the monomeric compounds in Table 2, whereas Nos. 20 and 26 in Fig. 5 did

284 not maintain the structure of phenylpropane side-chain. Generally, in hydrothermal

285 treatment, formaldehyde produced from lignocellulose forms diarylmethane structure

286 [31]. However, diarylmethane compound could not be found in GC-MS analysis. This

287 could be because semi-flow type treatment minimizes possible formation due to prompt

288 removal of the decomposed products.

289 In order to identify lignin-derived oligomeric compounds, MALDI-TOF/MS

290 analysis was performed. The obtained MALDI-TOF/MS spectra of the lignin-derived

291 products of the $1^{\text {st }}$ and $2^{\text {nd }}$ stages are shown in Fig. 6 . The spectra of the $1^{\text {st }}$ stage contain

292 several molecular weight intervals (MWIs) of 178 and 196. According to the experiment

293 with lignin model compounds, $\beta-\beta$ or $\beta-5$ linkage results in the MWI of 178 due to the

294 radical mechanism of coniferyl alcohol (MW: 180.20), whereas $\beta-O-4$ linkage results in

295 the MWI of 196 due to the addition of hydroxyl group [32]. Besides, some other

296 linkages such as 5-5, 4-O-5 and $\alpha-O-4$ linkages can result in the MWI of 178 as well.

297 Namely, the MWIs of 178 and 196 obtained from MALDI-TOF/MS spectra of the

298 lignin-derived products in the $1^{\text {st }}$ stage should be derived from coniferyl alcohol,

299 suggesting that the oligomeric lignin-derived products up to heptamers contain both

300 ether and condensed type linkages. In contrast, the spectrum of $2^{\text {nd }}$ stage does not 
301 contain the MWIs of 178 or 196, indicating that the phenylpropane side-chain could be

302 altered by hot-compressed water. The oligomeric lignin-derived products consisted up

303 to tetramer. These results really agree with those from GPC analysis.

Lignin-derived products in precipitate

306

307 The lignin-derived products in precipitate in both stages are composed of the higher

308 molecular weight products than water-soluble portion, and their structure was rich in

309 ether linkage according to the yield of vanillin by alkaline nitrobenzene oxidation (Fig.

3103 3). These results suggest that some micropores were produced in the cell wall due to the

311 decomposition of hemicelluloses and the cleavage of ether linkages in lignin in the $1^{\text {st }}$

312 stage, and the micropores would have facilitated the elution of the lignin cluster, which

313 maintains ether linkages [22]. Hydrophobic lignin could be eluted in hot-compressed

314 water due to the low dielectric constant of hot-compressed water, whereas some large

315 molecules cluster precipitated after hot-compressed water returned to the ordinary water

316 under ambient condition. In the $2^{\text {nd }}$ stage, cellulose- and lignin-derived oligomeric

317 compounds were also eluted in hot-compressed water. 
320 Lignin-derived products in water-insoluble residue

321

322 Approximately one third of original lignin still remained as water-insoluble residue after

323 two-step treatment, and the water-insoluble residue is $0.875 \mathrm{~g} / \mathrm{g}$ in lignin concentration

324 as in Table 1. The ratio of condensed type linkages was observed to increase as the

325 hot-compressed water treatment was prolonged. Consequently, lignin in the

326 water-insoluble residue after two-step treatment was rich in condensed type due to the

327 cleavage of ether type linkages and possible recondensation reaction. 


\section{Concluding remarks}

330 Decomposition behavior of lignin in Japanese cedar as treated by two-step semi-flow

331 hot-compressed water was discussed through the analyses of the lignin-derived products

332 fractionated during the treatment.

333 For the $1^{\text {st }}$ stage $\left(230{ }^{\circ} \mathrm{C} / 10 \mathrm{MPa} / 15 \mathrm{~min}\right)$, in which hemicelluloses and a part of

334 cellulose were decomposed, approximately half of lignin was decomposed and eluted in

335 hot-compressed water. Due to the decomposition of hemicelluloses and the cleavage of

336 ether linkages in lignin, some micropores would be occurred in the cell wall, which

337 would have facilitated the elution of the lignin cluster together with

338 hemicelluloses-derived products. The hydrophobic lignin could be, thus, eluted in

339 hot-compressed water due to the low dielectric constant of hot-compressed water. After

340 its elution, cluster of some large molecules were precipitated under ambient condition.

341 Since the precipitated lignin contained ether linkages, it would be considered to

342 maintain the structure of original lignin. On the other hand, lignin-derived products in

343 water-soluble portion were low molecular weight up to heptamers, and identified

344 monomeric compounds maintained methoxyl and phenolic hydroxyl groups such as

345 coniferyl alcohol, coniferyl aldehyde and vanillin.

346 For the $2^{\text {nd }}$ stage $\left(270{ }^{\circ} \mathrm{C} / 10 \mathrm{MPa} / 15 \mathrm{~min}\right)$, in which the rest of cellulose was mostly 
347 decomposed, a part of lignin was decomposed and eluted. As in the $1^{\text {st }}$ stage, some large

348 molecules of lignin clusters would be eluted and then precipitated under ambient

349 condition.

350 The rest of the remaining lignin to be one third of the original one had resistance to

351 hot-compressed water and remained as water-insoluble residue, which was mostly

352 composed of lignin. It is interesting that the remaining lignin rich in condensed type as

353 compared with untreated wood can be expected to be utilized as materials resistant to

354 any external attacks.

\section{Acknowledgements}

359 This work has been done as part of the JST (ALCA) project "Ethanol Production with

360 Acetic Acid Fermentation from Lignocellulosics". The authors gratefully acknowledge

361 all the support. 


\section{References}

364

365

1. Sarkanen KV, Hergert HL (1971) Classification and distribution. In: Sarkanen KV,

366 Ludwig $\mathrm{CH}$ (ed) Lignins. Occurrence, formation, structure and reaction.

367 Wiley-Interscience, New York, 43-94

368

2. Rogalinski T, Ingram T, Brunner G (2008) Hydrolysis of lignocellulosics biomass in water under elevated temperatures and pressures. J Supercrit Fluids 47: 54-63

370

3. Ando H, Sasaki T, Kokusho T, Shibata M, Uemura Y, Hatate Y (2000) Decomposition behavior of plant biomass in hot-compressed water. Ind Eng Chem Res 39: $3688-3693$

373

4. Tanahashi M, Karina M, Tamabuchi K, Higuchi T (1989) Degradation mechanism of lignin accompanying steam explosions I. Mokuzai Gakkaishi 35: 135-143

5. Ehara K, Takada D, Saka S (2005) GC-MS and IR spectroscopic analyses of the lignin-derived products from softwood and hardwood treated in supercritical water. $\mathbf{J}$ Wood Sci 51: 256-261

6. Takada D, Ehara K, Saka S (2004) Gas chromatographic and mass spectrometric (GC-MS) analysis of lignin-derived products from Cryptomeria japonica treated in supercritical water. J Wood Sci 50: 253-259 
382 in supercritical water and supercritical methanol. Sekiyu Gakkaishi 41: 243-250

383 8. Saisu M, Sato T, Watanabe M, Adschiri T, Arai K (2003) Conversion of lignin with

384 supercritical water - phenol mixtures. Energy Fuels 17: 922-928

385 9. Okuda K, Umetsu M, Takami S, Adschiri T (2004) Disassembly of lignin and

386 chemistry recovery - rapid depolymerization of lignin without char formation in

387 water - phenol mixtures. Fuel Process Technol 85: 803-813

388 10. Yokoyama C, Nishi K, Otake K, Takahashi S (1994) Thermolysis of dibenzyl ether

389 in supercritical methanol. Sekiyu Gakkaishi 37: 34-44

390 11. Yokoyama C, Yasuda T, Nishi K, Takahashi S (1996) Reactions of supercritical

391 water and supercritical methanol with benzaldehyde. Sekiyu Gakkaishi 39: 395-402

392 12. Martino CJ, Savage PE (1997) Thermal decomposition of substituted phenols in

393 supercritical water. Ind Eng Chem Res 36: 1385-1390

394 13. Sato T, Haryu E, Adschiri T, Arai K (2004) Non-catalytic of phenol through

395 decomposition of 2-isopropylphenol in supercritical water. Chem Eng Sci 59:

$396 \quad 1247-1253$

397 14. Thornton TD, Savage PE (1992) Kinetics of phenol oxidation in supercritical water.

$398 \quad$ AIChE J 38: 321-327

399 15. Townsend SH, Abraham MA, Huppert GL, Klein MT, Paspek SC (1988) Solvent

400 effects during reactions in supercritical water. Ind Eng Chem Res 27: 143-149 
401 16. Ehara K, Saka S, Kawamoto H (2002) Characterization of the lignin-derived

402 products from wood as treated in supercritical water. J Wood Sci 48: 320-325

403 17. Minami E, Kawamoto H, Saka S (2003) Reaction behavior of lignin in supercritical

404 methanol as studied with lignin model compounds. J Wood Sci 49: 158-165

405 18. Sasaki T, Shibata M, Sumi T, Yasuda S (2002) Saccharification of cellulose using a

406 hot-compressed water-flow reactor. Ind Eng Chem Res 41: 661-665

407 19. Liu C, Wyman CE (2003) The effect of flow rate of compressed hot water on xylan,

408 lignin, and total mass removal from Corn Stover. Ind Eng Chem Res 42: 5409-5416

409 20. Tirtowidjojo S, Sarkanen KV, Pla F, McCarthy JL (1988) Kinetics of organosolv

410 delignification in batch and flow-through reactors. Holzforschung 42: 177-183

411 21. Lu X, Yamauchi K, Phaiboonsilpa N, Saka S (2009) Two-step hydrolysis of

412 Japanese beech as treated by semi-flow hot-compressed water. J Wood Sci 55:

$413 \quad 367-375$

414 22. Yamauchi K, Phaiboonsilpa N, Kawamoto H, Saka S (2013) Characterization of

415 lignin-derived products from Japanese beech wood as treated by two-step semi-flow

416 hot-compressed water. J Wood Sci 59: 149-154

417 23. Nakamura Y, Miyafuji H, Kawamoto H, Saka S (2011) Acetic acid fermentation

418 with Clostridium Thermoaceticum and Clostridium Thermocellum of standard

419 compounds found in beech wood as produced in hot-compressed water. J Wood Sci 
24. Phaiboonsilpa N, Yamauchi K, Lu X, Saka S (2010) Two-step hydrolysis of Japanese cedar as treated by semi-flow hot-compressed water. J Wood Sci 56: $331-338$

25. Dence CW (1992) The determination of lignin. In: Lin SY, Dence CW (ed) Methods in Lignin Chemistry. Springer, Berlin, 33-39

26. Minami E, Saka S (2003) Comparison of the decomposition behaviors of hardwoods and softwoods in supercritical methanol. J Wood Sci 49: 73-78

27. Chen CL (1992) Nitrobenzene and cupric oxide oxidations. In: Lin SY, Dence CW (ed) Methods in Lignin Chemistry. Springer, Berlin, 301-312

28. Ehara K, Saka S (2002) A comparative study on chemical conversion of cellulose between the batch-type and flow-type systems in supercritical water. Cellulose 9: $301-311$

29. Meier D, Faix O (1992) Pyrolysis-gas chromatography-mass spectrometry. In: Lin SY, Dence CW (ed) Methods in Lignin Chemistry. Springer, Berlin, 177-199

30. Vane $\mathrm{CH}$ (2003) The molecular composition of lignin in spruce decayed by white-rot fungi (Phanerochaete chrysosporium and Trametes versicolor) using pyrolysis-GC-MS and phermochemolysis with tetramethylammonium hydroxide. Int Biodeter Biodegr 51: 67-75 
439 31. Brosse N, Hage EH, Chaouch M, Petrissans M, Dumarcay S, Gerardin P (2010)

440 Investigation of the chemical modifications of beech wood lignin during heat

441 treatment. Polym Degrad Stabil 95: 1721-1726

442 32. Yoshioka K, Ando D, Watanabe T (2011) A comparative study of matrix-and

443 nano-assisted laser desorption/ionization time-of-flight mass spectrometry of isolated

444 and synthetic lignin. Phyto Anal 23: 248-253

445 


\section{The list of figure and table captions}

447

448 Fig. 1 The yield of wter-soluble portion, precipitate and water-insoluble residue

449 composed of hemicelluloses, cellulose and lignin as treated by two-step semi-flow

450 hot-compressed water. The treatment temperature change is also shown.

451

452 Fig. 2 GPC chromatograms of the water-soluble portion and the precipitate in the $1^{\text {st }}$ stage (upper) and those in the $2^{\text {nd }}$ stage (lower)

454

455 Fig. 3 The yield of alkaline nitrobenzene oxidation products for the water-soluble

456 portion, precipitate and water-insolubl residue in the $1^{\text {st }}$ stage and $2^{\text {nd }}$ stage. Just

457 comparison, the yield of the untreated Japanese cedar is included.

458

459 Fig. 4 Total ion chromatogram of the water-soluble portion from Japanese cedar as

460 treated by semi-flow hot-compressed water by GC-MS. The numbers correspond to $461 \quad$ those in Tables 2 and 3.

462

463 Fig. 5 Speculative structures of some lignin-derived dimeric products. 
465 Fig. 6 MALDI-TOF/MS spectra of the lignin-derived products in the water-soluble

466 portion for the $1^{\text {st }}$ (upper) and $2^{\text {nd }}$ stages (lower) $(\mathrm{m} / z: 500-1400)$. Several molecular

467 weight intervals (MWI) of about 178.20 and 196.20 were obtained from the $1^{\text {st }}$ stage

468 water-soluble portion, suggesting $\beta-\beta$ or $\beta-5$, and $\beta-O-4$ linkages, respectively.

469

470 Table 1 The yields of fractionated product and lignin-derived product, and lignin

471 concentration in water-soulble portion, precipitate and water-insoluble residue in the

$472 \quad 1^{\text {st }}$ and $2^{\text {nd }}$ stages, as Japanese cedar treated by two-step semi-flow hot-compressed 473 water.

474

475 Table 2 Lignin-derived monomeric products in water-soluble portion and their 476 retention times, structures, and MS fragments for GC-MS analysis.

477

478 Table 3 Lignin-derived products in water-soluble portion and their retention times and 479 MS fragments for GC-MS analysis.

480 


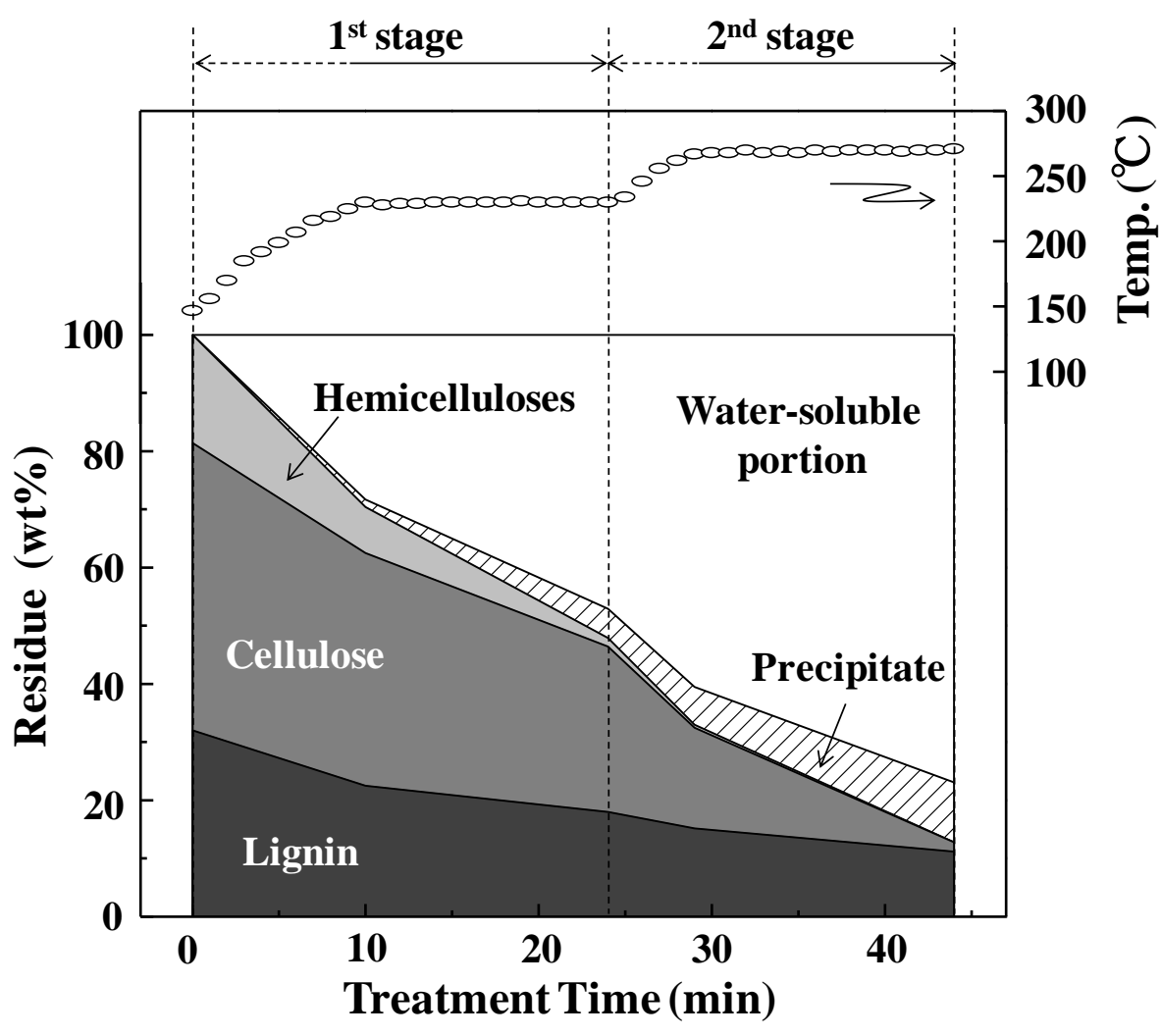

482

483 Fig. 1. The yield of water-soluble portion, precipitate and water-insoluble residue

484 composed of hemicelluloses, cellulose and lignin as treated by two-step semi-flow

485 hot-compressed water. The treatment temperature change is also shown.

486

487 


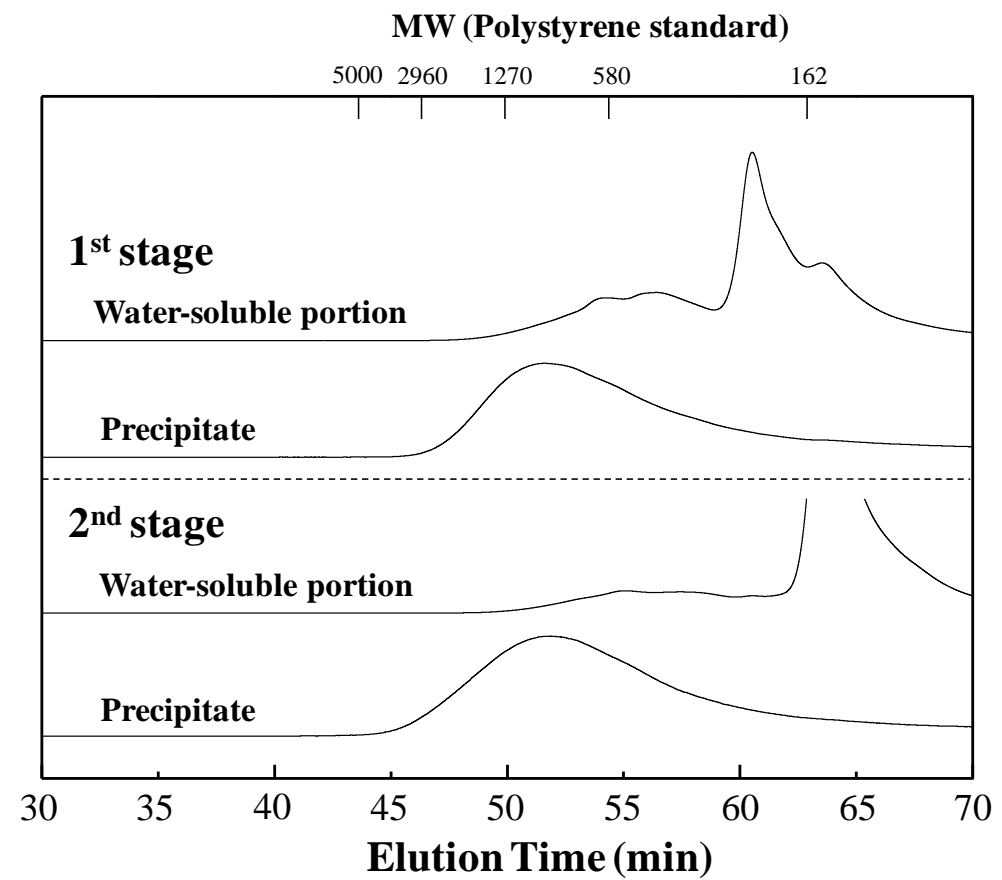

489 Fig. 2. GPC chromatograms of the water-soluble portion and the precipitate in the $1^{\text {st }}$

490 stage (upper), and those in the $2^{\text {nd }}$ stage (lower). 


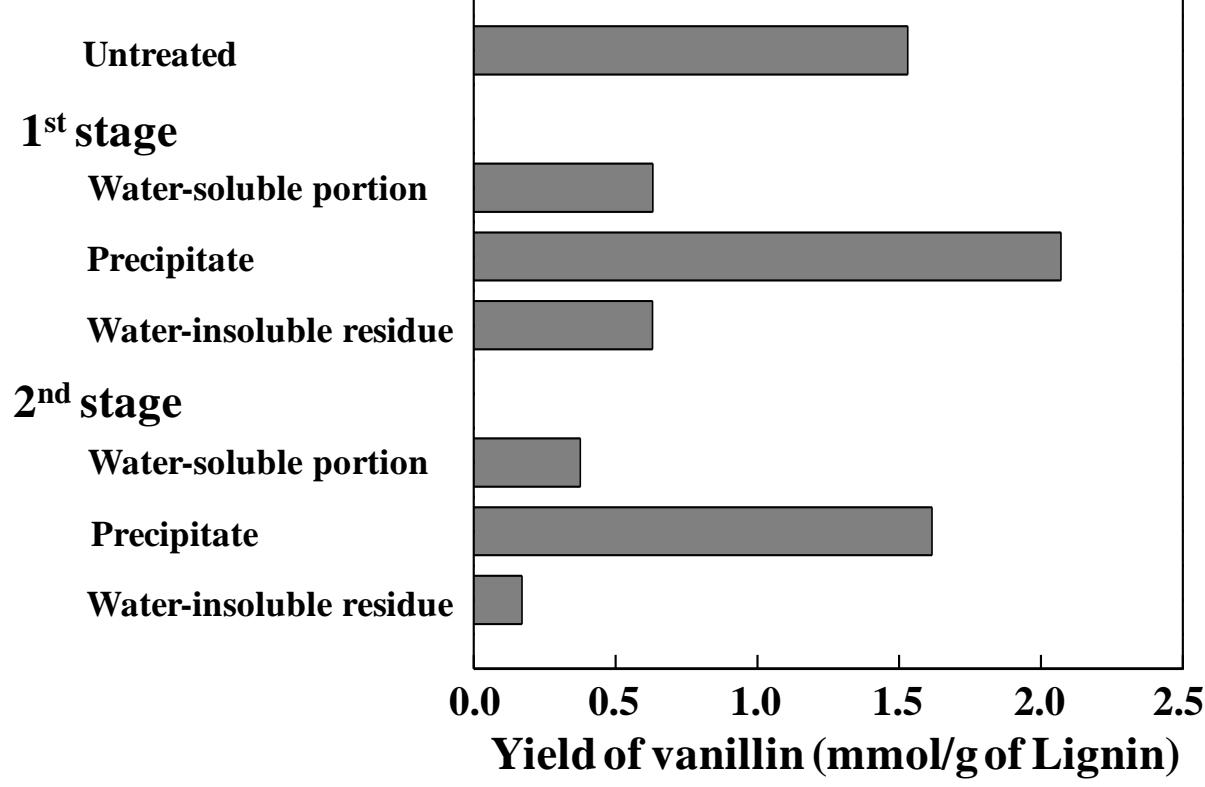

493 Fig. 3. The yield of alkaline nitrobenzene oxidation products for the water-soluble

494 portion, precipitate and water-insoluble residue in the $1^{\text {st }}$ stage and $2^{\text {nd }}$ stage. Just

495 comparison, the yield of the untreated Japanese cedar is included.

496 


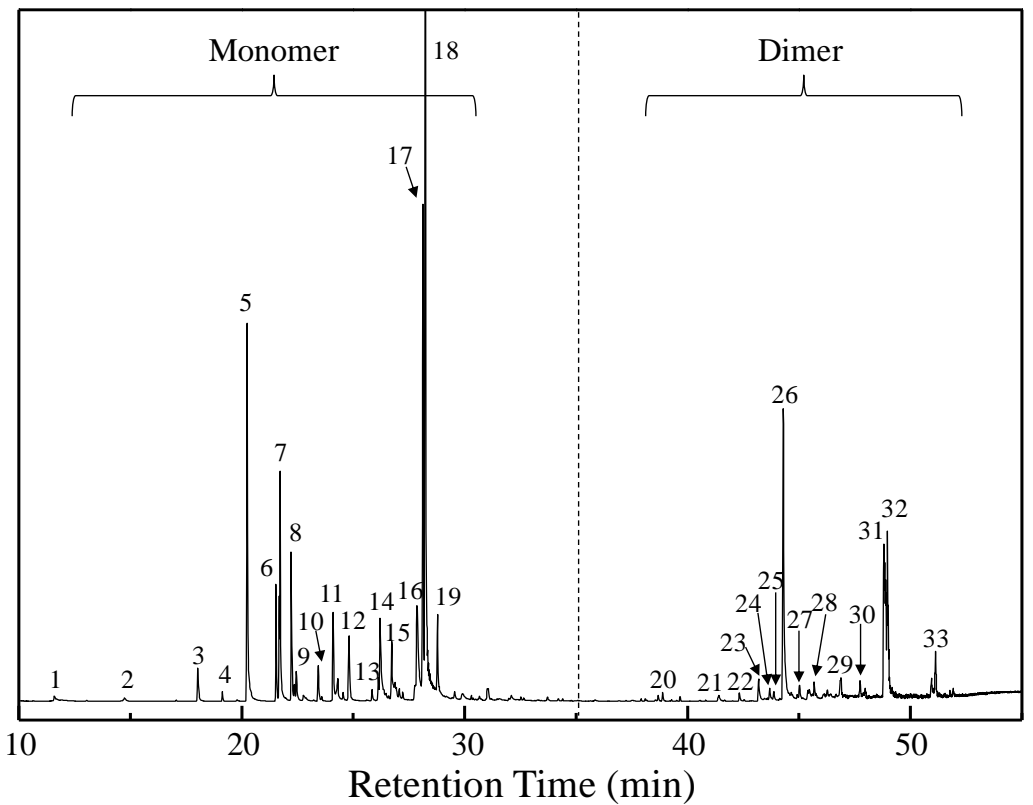

497

498 Fig. 4. Total ion chromatogram of the water-soluble portion from Japanese cedar as

499 treated by semi-flow hot-compressed water by GC-MS. The numbers correspond to

500 those in Tables 2 and 3.

501 
No. 20

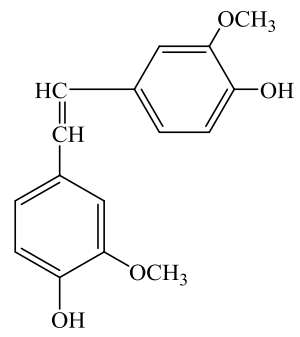

Stilbene type

$(\beta-1)$
No. 26<smiles>COc1cc(CCc2cccc(OC)c2OC)ccc1O</smiles>

Phenylcoumaran type

$(\beta-5)$
No. 31<smiles>CC=Cc1cc(OC)c(O)c(-c2cc(C=CC)cc(OC)c2O)c1</smiles>

Biphenyl type

(5-5')

505 Fig. 5. Speculative structures of some lignin-derived dimeric products.

506 


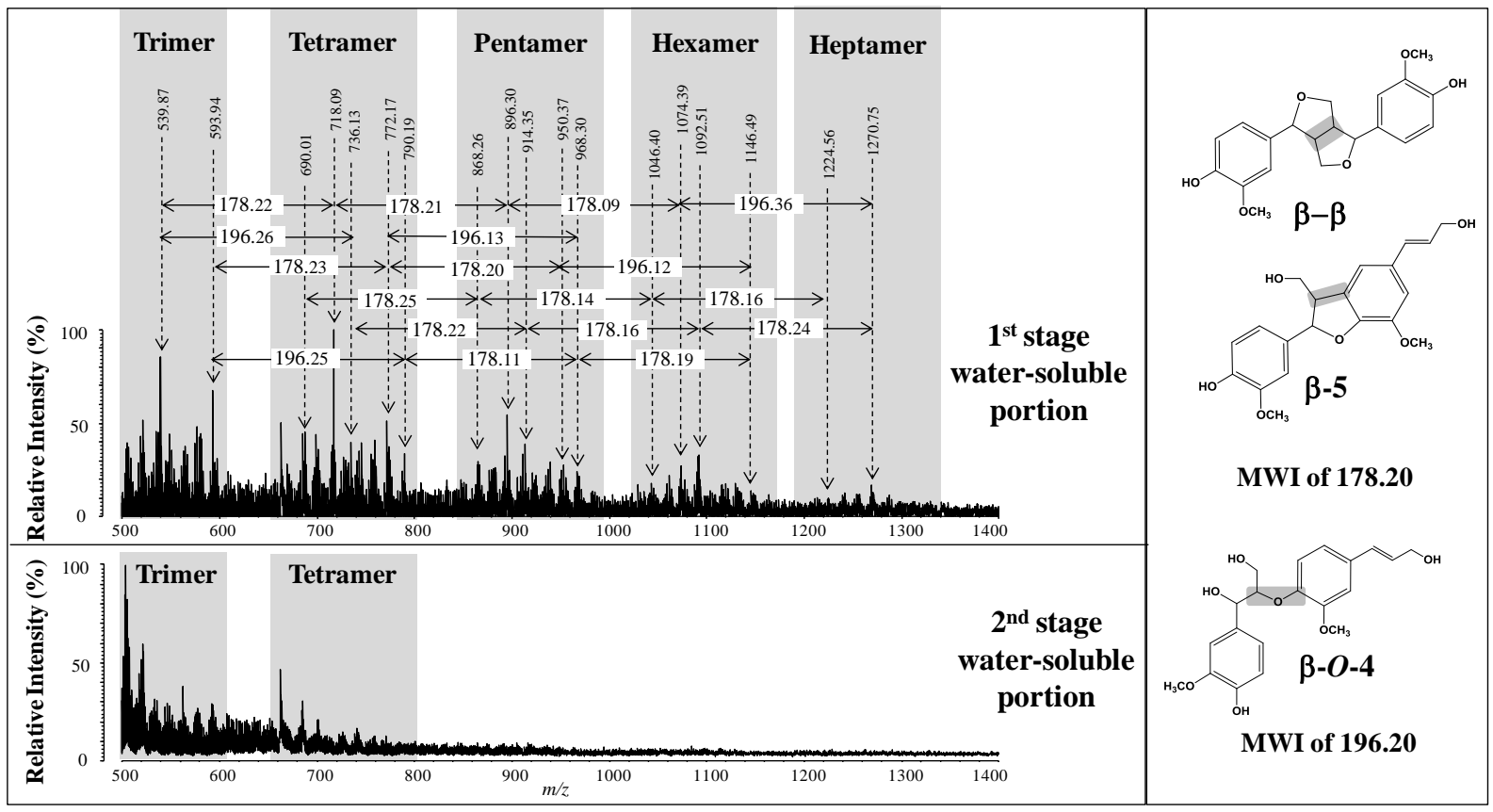

509

510 Fig. 6. MALDI-TOF/MS spectra of the lignin-derived products in the water-soluble

511 portion for the $1^{\text {st }}$ (upper) and $2^{\text {nd }}$ stages (lower) $(\mathrm{m} / z: 500-1400)$. Several molecular

512 weight intervals (MWI) of about 178.20 and 196.20 were obtained from the $1^{\text {st }}$ stage

513 water-soluble portion, suggesting $\beta-\beta$ or $\beta-5$, and $\beta-O-4$ linkages, respectively. 
515 Table 1. The yields of fractionated product and lignin-derived product, and lignin

516 concentration in water-soluble portion, precipitate and water-insoluble residue in the $1^{\text {st }}$

517 and $2^{\text {nd }}$ stages, as Japanese cedar treated by two-step semi-flow hot-compressed water.

518

\begin{tabular}{ccccc}
\hline Stage & Fraction & $\begin{array}{c}\text { Yield of fractionated } \\
\text { product } \\
\text { (wood-based wt\%) }\end{array}$ & $\begin{array}{c}\text { Yield of lignin-derived } \\
\text { product } \\
\text { (wood-based wt } \%)\end{array}$ & $\begin{array}{c}\text { Lignin } \\
\text { concentration* } \\
(\mathrm{g} / \mathrm{g})\end{array}$ \\
\hline \multirow{2}{*}{$1^{\text {st }}$ stage } & Water-soluble portion & 47.1 & 10.1 & 0.214 \\
& Precipitate & 5.0 & 3.9 & 0.780 \\
& Water-insoluble residue & 47.9 & 18.0 & 0.376 \\
\hline \multirow{2}{*}{$2^{\text {nd }}$ stage } & Water-soluble portion & 29.8 & 5.0 & 0.168 \\
& Precipitate & 5.3 & 1.8 & 0.340 \\
& Water-insoluble residue & 12.8 & 11.2 & 0.875 \\
\hline
\end{tabular}

$519 *$ Lignin concentration was obtained by the yield of lignin-derived product divided by that of

520 fractionated product.

521 
522 Table 2. Lignin-derived monomeric products in water-soluble portion and their retention

523 times, structures, and MS fragments for GC-MS analysis.

524

\begin{tabular}{|c|c|c|c|c|}
\hline No. & Product & $\begin{array}{l}\text { Retention Time } \\
(\mathrm{min})\end{array}$ & Structure ${ }^{* a}$ & MS fragments $(\mathrm{m} / \mathrm{z})$ \\
\hline 1 & Guaiacol & 11.6 & G & $124,109,89,81$ \\
\hline 2 & Methylguaiacol & 14.9 & $\mathrm{G}-\mathrm{C}$ & $138,123,95,77$ \\
\hline 3 & Vinylguaiacol ${ }^{* \mathrm{~b}}$ & 18.0 & $\mathrm{G}-\mathrm{C}=\mathrm{C}$ & $150,136,107,78$ \\
\hline 4 & Eugenol & 19.1 & $\mathrm{G}-\mathrm{C}-\mathrm{C}=\mathrm{C}$ & $164,149,134,104,77$ \\
\hline 5 & Vanillin & 20.3 & $\mathrm{G}-\mathrm{CHO}$ & $152,123,109,77$ \\
\hline 6 & trans-Isoeugenol & 21.5 & $\mathrm{G}-\mathrm{C}=\mathrm{C}-\mathrm{C}$ & $164,150,104$ \\
\hline 7 & Homovanillin & 21.7 & $\mathrm{G}-\mathrm{C}-\mathrm{CHO}$ & $166,138,123$ \\
\hline 8 & Unknown & 22.2 & & $162,148,120,92$ \\
\hline 9 & Acetovanillone & 22.4 & $\mathrm{G}-\mathrm{CO}-\mathrm{C}$ & 166,152 \\
\hline 10 & Guaiacylacetone*c & 23.4 & $\mathrm{G}-\mathrm{C}-\mathrm{CO}-\mathrm{C}$ & 180,137 \\
\hline 11 & Unknown & 24.1 & & $178,150,90,78$ \\
\hline 12 & 2-Methoxy-4-(prop-1-en-3-one)phenol ${ }^{* d}$ & 24.8 & $\mathrm{G}-\mathrm{CO}-\mathrm{C}-\mathrm{C}$ & 178,151 \\
\hline 13 & Homovanillic acid & 26.1 & $\mathrm{G}-\mathrm{C}-\mathrm{COOH}$ & 182,152 \\
\hline 14 & 3-4-Hydroxy-3-methoxyphenyl-1-propanol & 26.2 & $\mathrm{G}-\mathrm{C}-\mathrm{C}-\mathrm{C}-\mathrm{OH}$ & 182,138 \\
\hline 15 & cis-Coniferyl alcohol & 26.7 & $\mathrm{G}-\mathrm{C}=\mathrm{C}-\mathrm{C}-\mathrm{OH}$ & $180,163,138,124,78$ \\
\hline 16 & Hydroferulic acid & 27.8 & $\mathrm{G}-\mathrm{C}-\mathrm{C}-\mathrm{COOH}$ & 196,137 \\
\hline 17 & trans-Coniferyl aldehyde & 28.2 & $\mathrm{G}-\mathrm{C}=\mathrm{C}-\mathrm{CHO}$ & $178,164,149$ \\
\hline 18 & trans-Coniferyl alcohol & 28.4 & $\mathrm{G}-\mathrm{C}=\mathrm{C}-\mathrm{C}-\mathrm{OH}$ & $180,164,138$ \\
\hline 19 & Ferulic acid & 28.8 & $\mathrm{G}-\mathrm{C}=\mathrm{C}-\mathrm{COOH}$ & $194,167,138$ \\
\hline
\end{tabular}


529 Table 3. Lignin-derived dimeric products in water-soluble portion and their retention

530 times and MS fragments for GC-MS analysis.

531

\begin{tabular}{llll}
\hline No. & $\begin{array}{l}\text { Retention Time } \\
(\text { min })\end{array}$ & Product & MS fragments $(m / z)$ \\
\hline 20 & 38.7 & Stilbene type $(\beta-1)$ & $272,240,226,212,198,180,170,152,138,77,66$ \\
21 & 41.4 & $281,274,260,230,214$ \\
22 & 42.3 & $278,275,245,160,153,124,109,78,66,52$ \\
23 & 43.2 & $290,152,139,124,108,94,78,66$ \\
24 & 43.7 & Phenylcoumaran type $(\beta-5)$ & $272,241,225,213,212199,169$ \\
25 & 43.9 & $329,377,356,301,273,160,153,124,96,78,66,53$ \\
26 & 44.3 & $311,300,287,272,256,240,161,152,95,78,67$ \\
27 & 45.0 & & $358,313,298,282,253,210,181,162,79,52$ \\
28 & 45.7 & $357,341,313,286,269,208,175,160,152,137,78$ \\
29 & 46.9 & $344,326,312,207,139,121,93,78,66$ \\
30 & 47.7 & $326,312,298,266,190,177,162,139,124,104,92,78$ \\
31 & 48.8 & & $314,298,252,239,178,138,95,78$ \\
32 & 49.0 & Biphenyl type $(5-5)$ & $327,324,312,135,130,78$ \\
33 & 51.1 & & \\
\hline
\end{tabular}

